of antiplatelet agents following coronary artery bypass grafting. Controlled Clin Trials 1988;9:189-205.

3. Rajah SM, Nair U, Rees M, et al. Effects of antiplatelet therapy with indobufen or aspirin-dipyridamole on graft patency one year after coronary artery bypass grafting. $\mathbf{J}$ Thorac Cardiovasc Surg 1994;107:1146-53.

4. Van der Meer J, Hillege HL, Kootstra GJ, et al. Prevention of one-year vein-graft occlusion after aortocoronary-bypass surgery: a comparison of low-dose aspirin, low-dose aspirin plus dipyridamole, and oral anticoagulants. Lancet 1993;342:257-64.

5. Lemmer JH, Stanford W, Bonney SL, et al. Aprotinin for coronary bypass operations: efficacy, safety, and influence on early saphenous vein graft patency. J Thorac Cardiovasc Surg 1994;107:543-53.

12/8/59361

\section{Supernumerary heart valves}

\section{To the Editor:}

The report by Barbero-Marcial and associates ${ }^{1}$ on the surgical treatment of congenital mitral stenosis is a significant contribution. Their patient 7 , showing an accessory or supernumerary valve that should not be confused with any type of double-orifice mitral valve, is of special interest. My colleagues and $\mathrm{I}^{2}$ reported the pathologic description of a similar anomaly some years ago; in our case, imperforate Ebstein's anomaly of the tricuspid valve was present, and the supernumerary valve was hypoplastic and connected a chamber situated posterior to the left atrium, which could be a part of the coronary sinus, with the left ventricle. As in the case reported by Barbero-Marcial and coworkers, our case showed a single papillary muscle that received all the chordae tendineae of the supernumerary valve and was covered by the posterior leaflet of the left atrioventricular valve. Diagnosis in our case might also have been made through a left ventriculotomy, if the anomaly had been at all suspected. Resection of the atrial wall, as done in the case of BarberoMarcial, would have produced a communication of the coronary sinus and the right atrium with the left atrium, although of relatively small size. Closure of this communication would have been necessary to achieve complete correction.

Supernumerary valves are exceptional anomalies, thus far of mainly pathologic interest, that can be found in different locations. ${ }^{1-4}$ Premortem diagnosis is difficult, knowledge of the existence of these anomalies being the first requisite for diagnosis. Abnormal recesses in the atria and coronary sinus and bizarre communications between chambers should stimulate a search for supernumerary valves. Some of them, as very nicely shown by Barbero-Marcial and associates, could be physiologically useful after repair. Recognition and treatment of these anomalies would have been almost impossible without opening the left ventricle, and this reinforces the value of the report by Barbero-Marcial's group.

Eduardo Otero-Coto, $M D, P h D$

Service of Cardiovascular Surgery Hospital Clínico Universitario Avda. Blasco Ibañez 17 46010 Valencia, Spain

\section{REFERENCES}

1. Barbero-Marcial M, Riso A, DeAlbuquerque AT, Atik E, Jatene A. Left ventricular apical approach for the surgical treatment of congenital mitral stenosis. J THoRaC Cardiovasc Surg 1993;106:105-10.

2. Otero-Coto E, Quero M, Deverall PB. Rare anomalies of atrioventricular connection: hidden or supernumerary valves with imperforate right atrioventricular connection. Int J Cardiol 1984;6:149-56.

3. Otero-Coto E, Wilkinson JL, Dickinson DF, Rufilanchas JJ, Márquez J. Gross distortion of atrioventricular and ventriculo-arterial relations associated with left juxtaposition of atrial appendages: bizarre form of atrioventricular criss-cross. Br Heart J 1979;41:486-92.

4. Gerlis LM, Anderson RH, Dickinson DF. Duplication of the left atrioventricular valve in double inlet left ventricle: A triple inlet ventricle? Int $\mathrm{J}$ Cardiol 1984;6:157-61.

$12 / 8 / 58206$

\section{Reply to the Editor}

We appreciate the comments by Dr. Otero-Coto regarding our article "Left Ventricular Apical Approach for the Surgical Treatment of Congenital Mitral Stenosis." This technique had been used since 1987 in our institution to treat complex types of mitral stenosis such as parachute mitral valve. The removal of the obstruction starts from below; the papillary muscle is split, and the chorda is divided, resected, or fenestrated. After good visualization of the chordal insertion in the ventricular aspect of the mitral valve, the commissurotomies are made.

The patient who prompted the comments by Dr. Otero-Coto had a double mitral apparatus with independent mitral anuli. One hypoplastic mitral valve in the medial position had a supravalvular ring and joined the atrium to the left ventricle, ending in a single papillary muscle. The other mitral valve in the lateral position was parachute shaped and less hypoplastic, but was not connected to the left atrium. A true atrial wall separated this valve from the left atrium. Dr. OteroCoto's patient had a similar anomaly with imperforate Ebstein's anomaly of the tricuspid valve. The tricuspid valve was the supernumerary valve, hypoplastic and related posteriorly to the coronary sinus.

The risk of producing a communication between of the coronary sinus and the right atrium after the resection of the true atrial wall was not confirmed in our case because there was no close relation between this supernumerary valve and the coronary sinus. This could be because of its predominantly lateral position instead of posterior position. Overall, we agree with Dr. Otero-Coto that the resection of atrial wall could, in some cases, produce a communication between the coronary sinus and the right atrium.

\section{Miguel Barbero Marcial, MD Heart Institute University of São Paulo Caixa Postal 8091 São Paulo, Brazil 12/8/61481}

